Bernd J. Hartmann

\title{
Öffentliches Haftungsrecht
}

\section{Ökonomisierung - Europäisierung - Dogmatisierung}

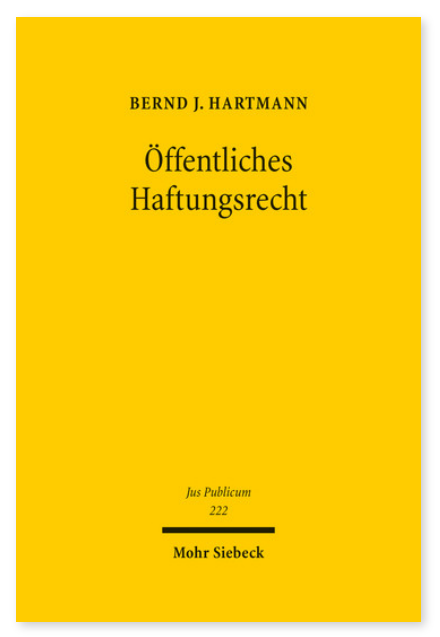

2013. XIX, 484 Seiten. JusPubl 222

ISBN 978-3-16-152526-1

DOI 10.1628/978-3-16-152526-1

eBook PDF 144,00€

ISBN 978-3-16-152525-4

Leinen $144,00 €$
Das Staatshaftungsrecht, das besser Öffentliches Haftungsrecht hieße, ist ein verrufenes Rechtsgebiet, chaotisch und zersplittert, ein »Flickenteppich« und ein »Durcheinander « zugleich. Diese Abhandlung sinnt auf Abhilfe. Sie schlägt eine neue Dogmatik vor, die das Öffentliche Haftungsrecht zu systematisieren sucht und der ein ökonomisch informierter und unionsrechtlich inspirierter Einheitsanspruch zu Grunde liegt. Der Einheitsanspruch berücksichtigt die Konvergenzen, die im herkömmlichen Staatshaftungsrecht zu beobachten sind, und nimmt Vorwürfe der Sach- und Zeitwidrigkeit auf, die gegen das überkommene Staatshaftungsrecht erhoben werden. Die Schrift wurde in Münster mit dem Habilitationspreis der Juristischen Studiengesellschaft und dem Nachwuchsförderpreis der Universitätsgesellschaft ausgezeichnet.

Bernd J. Hartmann Geboren 1973; Inhaber des Lehrstuhls für Öffentliches Recht, Wirtschaftsrecht und Verwaltungswissenschaften an der Universität Osnabrück; Mitglied der Wissenschaftlichen Leitung der Forschungsstelle Glücksspiel, Universität Hohenheim.

https://orcid.org/0000-0001-5380-4449
Jetzt bestellen:

https://mohrsiebeck.com/buch/oeffentliches-haftungsrecht-9783161525261?no_cache=1

order@mohrsiebeck.com

Telefon: +49 (0)7071-923-17

Telefax: $+49(0) 7071-51104$ 